\title{
INTERNATIONAL JOURNAL OF PLANT, ANIMAL AND ENVIRONMENTAL SCIENCES
}

IJPAES

\author{
Volume-6, Issue-3, July-Sept-2016 Coden: IJPAJX-CAS-USA, Copyrights@2016 ISSN-2231-4490 \\ Received: $30^{\text {th }}$ Apr $2016 \quad$ Revised: $18^{\text {th }}$ June $2016 \quad$ Accepted: $28^{\text {th }}$ June 2016 \\ DOI: 10.21276/Ijpaes http://dx.doi.org/10.21276/ijpaes \\ Research article
}

\section{COMPARATIVE EVALUATION OF VARIETIES OF COWPEA AND ITS EFFECT ON FERTILTY STATUS OF LATERITIC SOIL OF LANDMARK UNIVERSITY}

\author{
Adegbite KA, Dunsin O* and Adegoke IP \\ *Department of Crop and Soil Science, Landmark University, P. M. B. 1001, Omu-Aran, Nigeria.
}

\begin{abstract}
Identification of cowpea varieties with superior grain yield and high soil fertility enhancing potential is crucial to increasing productivity of the crop among small-scale farmers in Omu-Aran, Kwara State. A field experiment was carried out during the 2014 growing season to evaluate two cowpea varieties for their grain yield and their effect on fertility status of Lateritic soils of Landmark University Teaching and Research Farm. The varieties evaluated were IAR 48 and IAR 2.5.6. Variety IAR 2.5.6 produced the highest grain yield compared to variety IAR 2.5.6. The study also revealed the potential of cowpea in improving the fertility status of Lateritic soils as there was significant difference observed in some of the chemical properties analyzed including available Phosphorus, Exchangeable Calcium, Magnesium, Potassium and Sodium.
\end{abstract}

Key words: Lateritic soil; Cowpea; Fertility status.

*Corresponding author: Dunsin O, Department of Crop and Soil Science, Landmark University, P. M. B. 1001, Omu-Aran, NigeriaＥmail: Dunsin.oluwagbenga@lmu.edu.ng

Copyright: (02016 Dunsin O. This is an open-access article distributed under the terms of the Creative Commons Attribution License@ w $@$, which permits unrestricted use, distribution, and reproduction in any medium, provided the original author and source are credited

\section{INTRODUCTION}

Health of African soils has become a constant challenge for farmers and agriculturists in the continent. Conflicting interests in the exploitation of soil resources by various stakeholders has led to mismanagement; and in some cases degradation of soils. In recent decades, unsustainable land cultivation practices (e.g. inadequate replacement of soil nutrients taken up by crops) have led to accelerated depletion of the natural soil base available for food production [1]. According to [2], Nigeria is one of the countries with high declining soil fertility. The country was estimated to

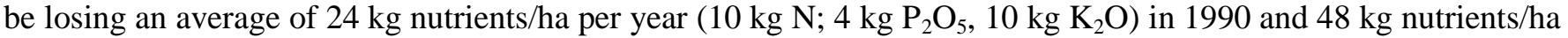
per year in 2000, that is, a loss equivalent to $100 \mathrm{~kg}$ fertilizers/ha per year. However in Figures $1 \& 2$ postulated to have dropped appreciably since the government and other foreign organizations started investing heavily on fertilizer. Soils in most parts of Nigeria have inherently low fertility and do not receive adequate nutrient replenishment. With Nigeria falling under sub-Saharan African countries with low mineral fertilizer consumption, about $10 \mathrm{~kg}$ nutrients $\left(\mathrm{N}, \mathrm{P}_{2} \mathrm{O} 5, \mathrm{~K}_{2} \mathrm{O}\right) / \mathrm{ha}$ per year, compared to the world average of $90 \mathrm{~kg}, 60 \mathrm{~kg}$ in the Near East and $130 \mathrm{~kg} / \mathrm{ha}$ per year in Asia, soil productivity maintenance remains a major environmental issue in countries of Sub-Saharan Africa. Low soil fertility inevitably leads to low agricultural productivity, since agricultural development is fundamentally affected by productivity status of land resources. Poor soil management and the fragile nature of tropical soils generally account for heavy nutrient losses through soil erosion and nutrient leaching in soils [1].

Lateritic soils are described as product of highly weathered material, under tropical and subtropical conditions, rich in secondary oxides of iron, aluminium or both. They are nearly void of bases and primary silicates, but may contain amounts of quartz or kaolinite. Also, the lateritic soils are either hard or capable of hardening on exposure to wetting and drying. Furthermore, the lateritic soils are composed of a wide variety of red, brown, and yellow fine-grained residual soils of light texture, as well as nodular gravels and cemented soils [3]. 
The agricultural value of lateritic soils depends largely on the thickness of the overlying surface material. Those soils having concretionary layers below $50 \mathrm{~cm}$ depth were categorized to be moderately productive for paddy and other cereal crops. While in terms of physical and chemical properties the highly weathered lateritic soils were mostly rated poor for agriculture because of their compacted B-horizon which inhibits root penetration with relatively low moisture [4]. Red and lateritic soils are generally acidic and have low cation exchange capacity (CEC) and low to moderate base saturation [5]. These soils are dominated by kaolinite clay and rich in sesquioxides. Surface crusting, poor inherent fertility, P fixation, aluminium toxicity, soil erosion among others are the major constraints in these soils [6].

Cowpea is a dicotyledonous plant belonging to the family Fabaceae and sub-family, Fabiodeae. It is grown extensively in the low lands and mid-altitude regions of Africa (particularly in the dry savanna) sometimes as sole crop but more often intercropped with cereals such as sorghum or millet [7]. World production of cowpea was estimated to be 2.27 million tons of which Nigeria produces about 850,000 tonnes [8]. Cowpea like all other legumes also improves soil fertility by converting atmospheric nitrogen from the soil for its own use, which also benefits subsequent crops in rotation. It therefore cuts down the amount of nitrogen fertilizer that farmers have to purchase to apply to their fields to improve productivity. Cowpea is more tolerant of low fertility, due to its high rates of nitrogen fixation, effective symbiosis with mycorrhizae, and ability to better tolerate soils over a wide range of $\mathrm{pH}$ when compared to other popular grain legumes. Therefore, the primary objective of the research is to investigate the amount of nitrogen contributed to the lateritic soils of Landmark University Research Farm through fixation by cowpea, and to attempt to determine the nitrogen budget of the soils after cropping with cowpea.

In the course of the project, an assessment of the performance of two varieties of cowpea (IAR 48 and IAR 2.5.6) on the lateritic soils was made. The project site is situated in Omu-Aran some 88 kilometers South of Ilorin, capital of Kwara State and $16 \mathrm{~km}$ North-East of Otun Ekiti, in Ekiti State, Nigeria. It is located on Latitude $8.9^{0} \mathrm{~N}$ and Longitude $5.16^{\circ} \mathrm{E}$. The town shares boundaries with Iloffa and Odo-Owa in the East, Ipetu-Igbomina and Arandun in the South, Oke-Onigbin in the West, Oko and Isanlu-Isin in the North-West respectively, all in Kwara state (Geography of Omu-Aran, 2007-2011). The climate of the area is tropical with pronounced wet and dry seasons and steady high temperatures. It receives a mean annual rainfall of 1,244 mm.

\section{MATERIALS AND METHODS}

The planting material was sourced from Federal Department of Agriculture, Ilorin, Nigeria. Two cowpea varieties were acquired; IAR48 and IAR2.5.6 3.3.3. The planting was carried out on the $12^{\text {th }}$ of August 2014. The planting distance was $50 \mathrm{~cm}$ by $20 \mathrm{~cm}$ and the seed rate was 3 seeds per planting hole at a depth of 2.5 to $5 \mathrm{~cm}$. The total land area for the experiment was $60 \mathrm{~m}^{2}$. Thinning out was done to approximately 2 plants per stand at two weeks after planting. The following growth parameters were measured every two weeks during the planting period. They include Plant height, Number of Leaves, Stem girth, pod length, Number of seeds per pod, number of pods per plant and average yield per plot.

Soil samples were collected from the experimental site before planting and after harvesting at a soil sampling depth of 0-15 cm. The soil samples were analyzed at the Crop and Soil Science laboratory, Landmark University, OmuAran, Kwara state, Nigeria. The particle size analysis was determined by the hydrometer method. Exchangeable calcium, magnesium, potassium and sodium were extracted with neutral normal ammonium acetate. Calcium and magnesium in the $\mathrm{NH}_{4} \mathrm{OAc}$ solution were determined by atomic absorption spectrophotometry, while $\mathrm{K}$ and $\mathrm{Na}$ were determined by flame photometry. Available phosphorus (Bray 1) was determined using Murphy and Riley (1962) reagent. Organic matter was determined by Walkey and Black method (Jackson 1958). Effective CEC was the summation of $\mathrm{NH}_{4} \mathrm{OAc}$ bases and $\mathrm{KCl}$ exchangeable $\mathrm{Al}$ and $\mathrm{H}[9,10]$. The $\mathrm{pH}$ was determined with the glass electrode $\mathrm{pH}$ meter in soil: water and soil: $\mathrm{KCl}$ media, each of ratios 1:2. 


\section{RESULTS AND DISCUSSIONS}

Soil Physical and Chemical Properties before and after Harvesting

Table 1: Table showing the physical and chemical properties before and after harvesting

\begin{tabular}{|c|c|c|c|c|}
\hline \multirow{2}{*}{ VARIABLE } & \multicolumn{2}{|c|}{ Soil Samples } & \multirow{2}{*}{$\begin{array}{l}\text { T test } \\
\text { Value }\end{array}$} & \multirow{2}{*}{ SIGNIFICANCE } \\
\hline & Before Planting & After Harvesting & & \\
\hline Sand & 97.96 & 98.02 & -0.48 & NS \\
\hline Silt & 0.16 & 0.17 & -0.16 & NS \\
\hline Clay & 1.88 & 1.82 & 0.52 & NS \\
\hline $\mathrm{pH} \mathrm{H} \mathrm{H}_{2} \mathrm{O}$ & 5.28 & 5.49 & -1 & NS \\
\hline $\mathrm{pH} \mathrm{CaCl}$ & 4.12 & 4.01 & 1.39 & NS \\
\hline$\% \mathrm{TN}$ & 0.58 & 0.36 & 1.03 & NS \\
\hline$\% \mathrm{TC}$ & 2.07 & 1.89 & 0.65 & NS \\
\hline$\% \mathrm{OM}$ & 3.58 & 3.25 & 0.66 & NS \\
\hline Av.Pmg/kg & 3.96 & 7.66 & -3.11 & $*$ \\
\hline $\mathrm{Ca}$ & 5.88 & 6.81 & -2.98 & $*$ \\
\hline $\mathrm{Mg}$ & 0.037 & 0.115 & -5.69 & $* *$ \\
\hline $\mathrm{K}$ & 0.27 & 0.42 & -2.89 & $*$ \\
\hline $\mathrm{Na}$ & 1.17 & 1.1 & 0.76 & NS \\
\hline $\mathrm{Al}+\mathrm{H}$ & 2.56 & 1.73 & 1.45 & NS \\
\hline $\mathrm{CEC}$ & 9.9 & 10.16 & -0.38 & NS \\
\hline $\begin{array}{l}\text { Base } \\
\text { Saturation }\end{array}$ & 74.97 & 83.29 & -1.85 & NS \\
\hline
\end{tabular}

$* *, *$ Significant at $1 \%$ and $5 \%$ respectively

NS, represents Not Significant

Table 2: Table showing the physical and chemical properties before and after harvesting

\begin{tabular}{|l|r|r|r|l|}
\hline \multirow{2}{*}{ VARIABLE } & \multicolumn{2}{|c|}{ Soil Samples } & \multicolumn{1}{c|}{$\begin{array}{c}\text { T test } \\
\text { Value }\end{array}$} & \multirow{2}{*}{ SIGNIFICANCE } \\
\cline { 2 - 3 } & Before Planting & After Harvesting & -0.48 & NS \\
\hline Sand & 97.96 & 98.02 & -0.16 & NS \\
\hline Silt & 0.16 & 0.17 & 0.52 & NS \\
\hline Clay & 1.88 & 1.82 & -1 & NS \\
\hline pH H${ }_{2} \mathrm{O}$ & 5.28 & 5.49 & 1.39 & NS \\
\hline pH CaCl & 4.12 & 4.01 & 1.03 & NS \\
\hline$\% \mathrm{TN}$ & 0.58 & 0.36 & 0.65 & NS \\
\hline$\% \mathrm{TC}$ & 2.07 & 1.89 & 0.66 & NS \\
\hline$\% \mathrm{OM}$ & 3.58 & 3.25 & -3.11 & $*$ \\
\hline $\mathrm{Av.Pmg} / \mathrm{kg}$ & 3.96 & 7.66 & -2.98 & $*$ \\
\hline $\mathrm{Ca}$ & 5.88 & 6.81 & -5.69 & $* *$ \\
\hline $\mathrm{Mg}$ & 0.037 & 0.115 & -2.89 & $*$ \\
\hline $\mathrm{K}$ & 0.27 & 0.42 & 0.76 & NS \\
\hline $\mathrm{Na}$ & 1.17 & 1.1 & 1.45 & NS \\
\hline Al+H & 2.56 & 1.73 & -0.38 & NS \\
\hline $\mathrm{CEC}$ & 9.9 & 10.16 & -1.85 & NS \\
\hline $\begin{array}{l}\text { Base } \\
\text { Saturation }\end{array}$ & 74.97 & 83.29 & & \\
\hline
\end{tabular}

$* *, *$ Significant at $1 \%$ and $5 \%$ respectively

NS, represents Not Significant

Physical properties before Planting and After Harvesting

The physical and chemical properties of the soil samples before and after harvesting are as shown in Table 1. Sand $(97.96 \%)$ is the dominant fraction of the soil. Therefore the textural class of the pretreated soil is Sandy soil. There was no noticeable change in texture after harvesting as Table 2 above shows that sand, silt and clay are $98.02 \%$, $0.17 \%$ and $1.82 \%$ respectively. 
Effect of Cowpea on the chemical properties of the soil before Planting and after Harvesting

Significant differences were observed in available phosphorus, and exchangeable cations (calcium, magnesium, potassium and sodium). No significant differences were observed in other parameters.

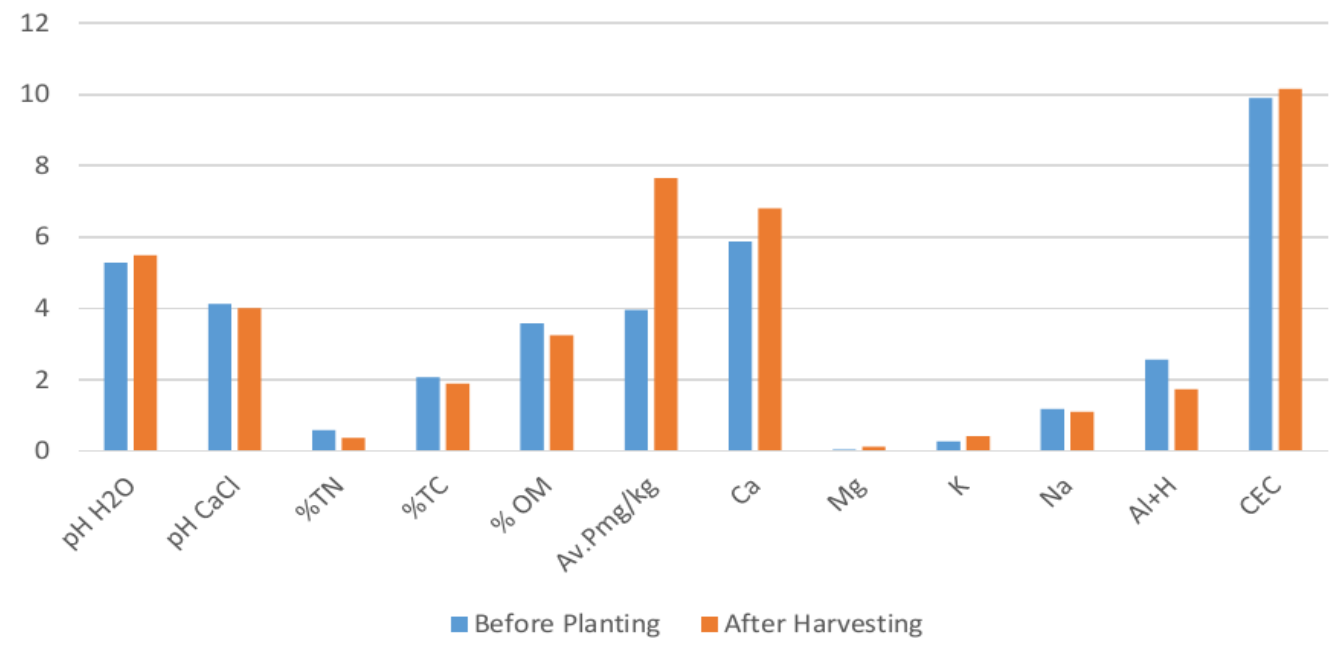

Figure 1: Significant differences between chemical properties of the soil before Planting and after Harvesting

This agrees with previous studies as they give conflicting report on the contribution of cowpea to soil fertility, particularly to soil N status. For instance, [11] found that the yield of maize from previous cowpea and cotton plots was low when compared to maize yields from previous groundnut plots. In Australia, observed that soil could deteriorate in cowpea fields because of little or no $\mathrm{N}$ addition when cowpea tops were removed from the field. Tucker \& Matlock also argued that cowpeas are soil depleting if the tops containing large amounts of major fertilizer elements are removed from the field. On the other hand, [12] reported in a review article that cowpea had a beneficial effect on a subsequent crop of maize in South Africa.

Table 3: Comparative evaluation of some Plant Parameters on two cowpea varieties (IAR256 and IAR48)

\begin{tabular}{|c|c|c|c|c|}
\hline \multirow{2}{*}{ VARIABLE } & \multicolumn{2}{|c|}{ VARIETY } & \multirow{2}{*}{ T test VALUE } & \multirow{2}{*}{ SIGNIFICANCE } \\
\cline { 2 - 3 } & IAR256 & IAR48 & & $*$ \\
\hline AYPP & 1.63 & 1.03 & 3.18 & $*$ \\
\hline NOPPP & 10.00 & 7.67 & 3.50 & $*$ \\
\hline NOSPP & 11 & 15.33 & -4.11 & $* *$ \\
\hline PL & 15.23 & 17.1 & -7.17 & \multirow{2}{*}{ * Significant at 1\% and 5\% respectively NS, Not Significant } \\
\hline
\end{tabular}

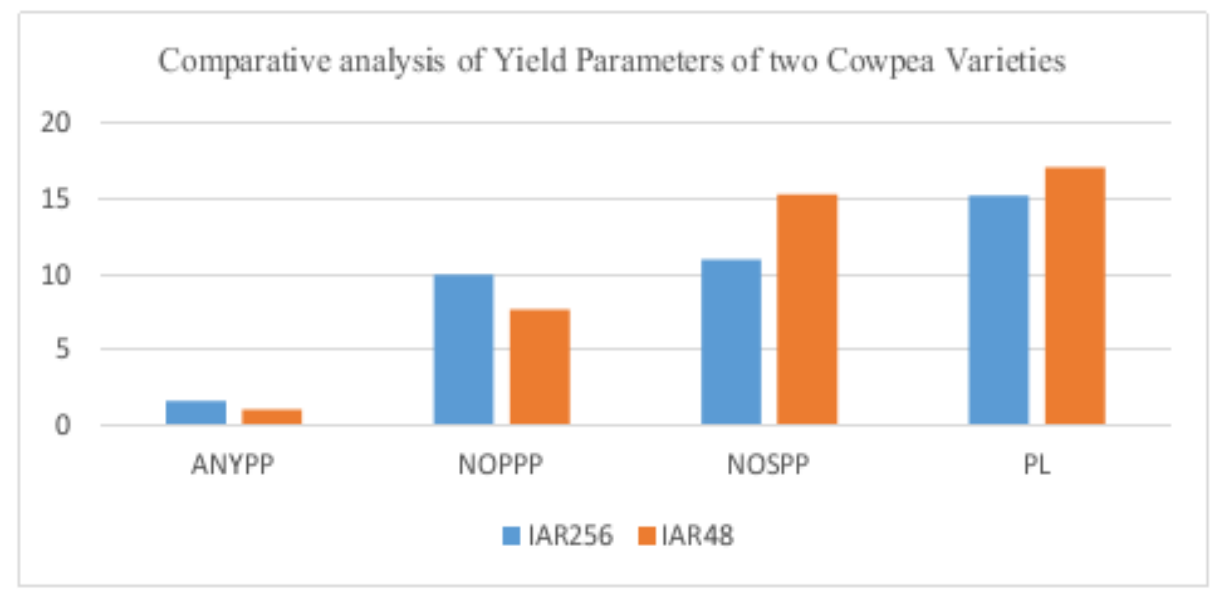

Figure 2: Comparative analysis of Yield parameters of two Cowpea varieties 
Results presented in Table 3 indicated that there was significant difference for all the yield parameters taken at harvest. Variety IAR 2.5.6 produced the highest average yield per plot and was significantly higher $(\mathrm{P}<0.05)$ than variety IAR48. This implies that the total yield of variety IAR2.5.6 is significantly higher than variety IAR48. Also, Variety IAR 2.5.6 produced the highest number of pod per plant (NOPPP), showing higher significance $(\mathrm{P}<0.05)$ than variety IAR48. The number of seeds per pod (NOSPP) for variety IAR48 was significantly higher $(\mathrm{P}<0.05)$ than variety IAR 2.5.6, it also showed observable higher numerical difference. Variety IAR48produced the highest pod length and was significantly higher $(\mathrm{P}<0.01)$ than variety IAR48.From the chart above, it also showed observable higher numerical difference.

\section{CONCLUSION}

The results of this study show that there were varying performance indices between both cowpea varieties. Significant differences in grain yield of the varieties indicate that, recommendations for cowpea varietal selection could be based on expected yield goals. The results indicate field based empirical evidence that, variety IAR 2.5.6 is superior in terms of yield performance on lateritic soils of Landmark University, Omu-Aran, in a derived savannah agro-ecological zone of Nigeria. It is therefore recommended over IAR 48 for producers if the expected goal is to achieve higher yields. Also, variety IAR 48 showed higher significant difference over IAR 2.5.6 in some of the growth parameters. At 10WAP, variety IAR 48 had higher leaf number, and at harvest it was significantly higher in Pod length and number of seeds per pod (NOSPP).

It is also recommended that the propagation of cowpea in improving soil fertility status should be employed in an integrated soil fertility improvement system by returning the crop residues to the soil.

\section{REFERENCES}

[1] Hossner LR, Juo ASR 1999. Soil Nutrient Management for Sustained Food crop Production in Upland Farming Systems in the Tropics. Juo Soil and Crop Sciences Department College Station Tennessee 77843, USA. Retrieved from http//www.agnet.org

[2] FAO 2001. Soil Fertility Management in Support of Food security in Sub-Saharan Africa. Available on ftp://ftp.fao.org/agl/agll/docs/foodsec.pdf Nigeria

[3] Bourman RP, Ollier CD 2002. A critique of the Schellmann definition and classification of laterite. Catena 47: 117-131.

[4] Raychaudhuri SP 1980. The occurrence, distribution, classification and management of laterite and lateritic soils. Coh. O.R.S.T.0 M, sér. PMol 18: 249-252.

[5] Buol SW, Cook MG 1998. Red and lateritic soils of the world: Concept, potential, constraints and challenges. Red and lateritic soils-Volume-1: Managing red and lateritic soils for sustainable agriculture, p: 49-56.

[6] Sehgal JL, Challa O, Thampi CJ, Maji AK, Bhushana SRN 1998. Red and lateritic soils of India. In Red and lateritic soils-Volume-2 Red and lateritic soils of the world p: 1-18.

[7] Agboola SA 1979. An Agricultural Atlas of Nigeria. Oxford University Press p: 29-31.

[8] Adaji MJ, Olufala OO, Aliyu L 2007. Effect of intra-row spacing and stand density on the growth and yield of cowpea (Vigna unguculata (L.) Walp).

[9] Adjei-Nsiah S, Kuyper TW, Leeuwis C, Abekoe MK, Cobbinah J, Sakyi-Dawson O, Giller KE 2008. Farmers' agronomic and social evaluation of productivity, yield and N2-fixation in different cowpea varieties and their subsequent residual N effects on succeeding maize crop. Nutr. Cycl. Agroecosyst 80: 199-209.

[10] FAO 2006. Plant nutrition for food security, a guide for integrated nutrient management. FAO Fertilizer and Plant Nutrition Bulletin. No.16: p 121, Rome, Italy.

[11] Jones MJ 1974. Effects of previous crop on yield and nitrogen response of maize at Samaro, Nigeria.

[12] Sellschop JPF 1962. Cowpeas, Vigna unguiculata (L.) Walp. Field Crop Abstr 15: 259-266. 
8. INTERNATIONAL IOURNAL OF

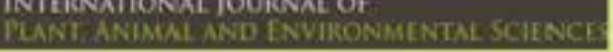

ISSN 2231-4490

International Journal of

Plant, Animal and

Environmental Sciences

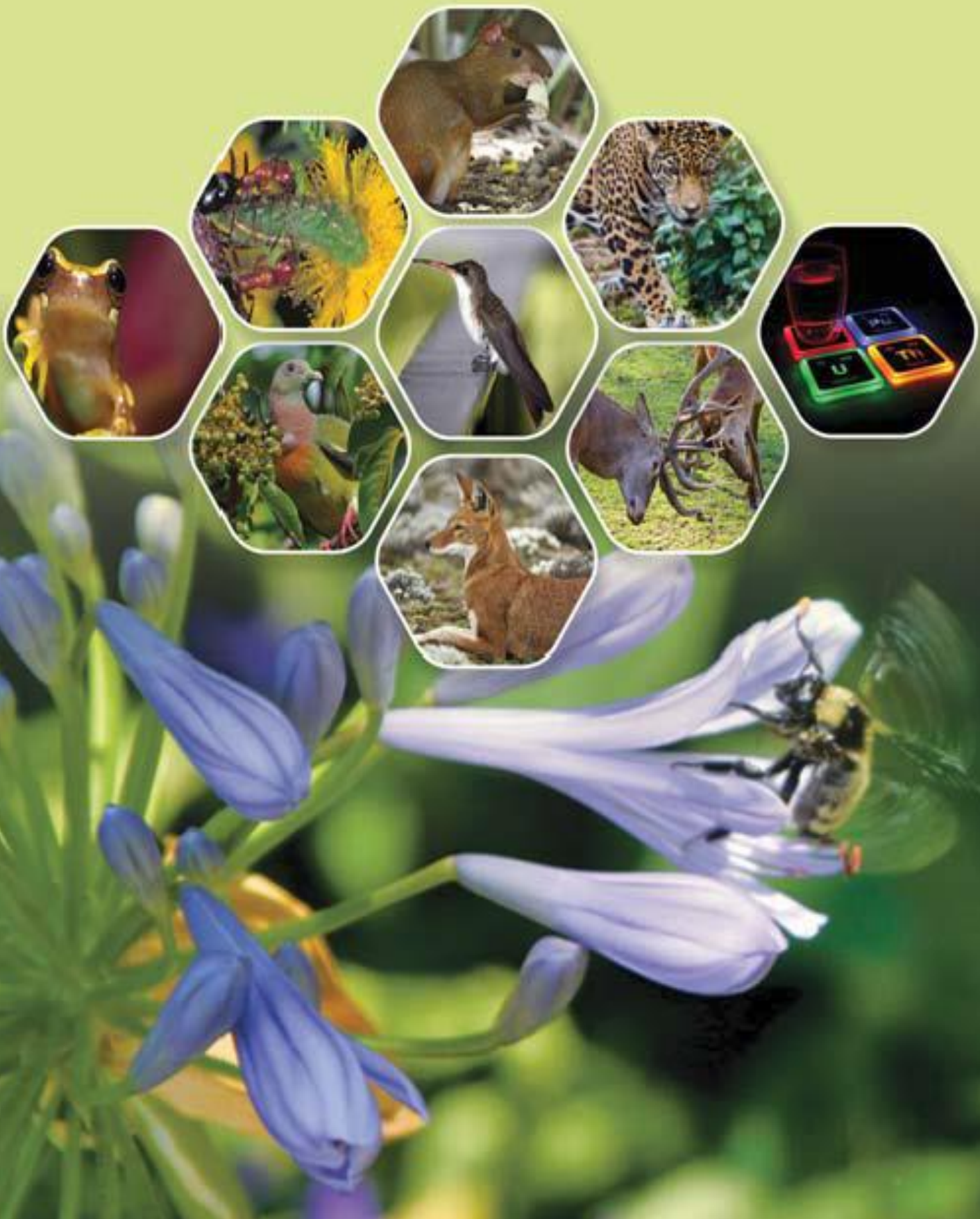

